\title{
Nutritional Status and Virological Outcomes of Children HIV Positive Attending Anti-Retroviral Clinic at University College Hospital, Ibadan
}

\author{
Chiamaka Okafor ${ }^{1}$, Grace Fadupin'1, Regina Oladokun ${ }^{2}$ \\ ${ }^{1}$ Department of Human Nutrition, Faculty of Public Health, College of Medicine, University of Ibadan, \\ Ibadan, Nigeria \\ ${ }^{2}$ Department of Paediatrics, Faculty of Clinical Sciences, College of Medicine, University of Ibadan, \\ Ibadan, Nigeria \\ Email: chiaugusta93@yahoo.com
}

How to cite this paper: Okafor, C., Fadupin, G. and Oladokun, R. (2021) Nutritional Status and Virological Outcomes of Children HIV Positive Attending Anti-Retroviral Clinic at University College Hospital, Ibadan. Food and Nutrition Sciences, 12, 1088-1097.

https://doi.org/10.4236/fns.2021.1211080

Received: October 19, 2021

Accepted: November 23, 2021

Published: November 26, 2021

Copyright $\odot 2021$ by author(s) and Scientific Research Publishing Inc. This work is licensed under the Creative Commons Attribution International License (CC BY 4.0).

http://creativecommons.org/licenses/by/4.0/

\begin{abstract}
Malnutrition has been reported as a major factor contributing to the poor outcome of effective ART in HIV infection. This study aimed to describe the relationship between the nutritional status and virological outcome of the children attending the antiretroviral clinic at University College Hospital (UCH) Ibadan, Nigeria. Among the 159 (55.3\% males and 44.7\% females) children studied, almost half (42.8\%) were orphans and the majority $56.6 \%$ were aged 120 - 180 months old. More than half (74.2\%) had achieved viral suppression and significant associations were observed between viral load and stunting as well as between $\mathrm{CD} 4$ count and the age of the children $(\mathrm{P}<0.05)$. The prevalence of stunting, wasting, and underweight was $27.7 \%, 9.4 \%$, and $13.6 \%$ respectively. These indices reinforce the need for nutrition education and the provision of food supplements to improve the nutritional status of children infected with HIV.
\end{abstract}

\section{Keywords}

Dietary Pattern, Nutritional Status, HIV, Children, Nutrient Intake

\section{Introduction}

Childhood and adolescence is a time of active growth in terms of physical size, mental, emotional and psychological development. Malnutrition is one of the major public health challenges in developing countries and may predispose one 
to infections. Populations mostly affected are infants and young children due to their increased nutritional needs to support growth and development [1]. Reducing childhood undernutrition remains a major challenge in all regions and especially among middle income and low income countries. Malnutrition is a common complication of HIV [2] and a significant cause of childhood morbidity and mortality (alone and in combination with other illnesses in sub Saharan Africa [3]. An estimated $2.5 \%$ of all child deaths are associated with HIV infection and Africa is the region largely affected, with $5 \%$ of all child deaths associated with HIV infection [4]. Nigeria accounted for 59\% of all new child HIV infections in west and central Africa in 2016 [5]. The interaction between malnutrition and HIV infection is complicated but it may place additional stress on an already weakened immune system and may complicate the treatment of the disease by affecting the ability of the intestinal tract to absorb drugs and also the ability to absorb various nutrients [2]. Malnutrition places a high demand on the bodies and immune system of the children. Introduction of antiretroviral therapy (ART) has reduced the mortality rates globally [6] through suppression of viral replication and HIV disease progression among patients receiving ART. However antiretroviral therapy access, particularly among children is still lagging. In addition, many of the low- and middle-income countries still face significant challenges, including higher mortality in the first few months following the initiation of ART [7] [8]. ART has improved the survival of HIV-infected children but there is still an increasing challenge of managing various aspects of the care of these children and nutrition is one of the most important aspects. Immediate initiation of ART is recommended and has improved the overall prognosis of HIV infection. In Nigeria, it is evident that malnutrition is still a major public health problem among young children due to the poor socioeconomic status (poverty and poor educational background) of their parents, and thus, there is a need for better nutrition of the Nigerian child [9]. Nutritional status and immunological competence are among the most important determinants of morbidity and mortality. In 2018, the UNAIDS [5] estimated that there were about 37.9 million (32.7 million - 44.0 million) people living with HIV 36.2 million adults and about 1.7 million (1.3 million - 2.2 million) children (<15 years). Nigeria currently has the largest burden of paediatric HIV infection in the world, with an estimated 321,000 children living with the human immunodeficiency virus (HIV) in Nigeria as at 2010 [10]. The study was therefore designed to provide baseline information on the health and nutritional status of the target group, by determining the correlation between the nutritional status and virological outcomes of children living with HIV in the study location.

\section{Methods}

\subsection{Study Population}

The study was a hospital based cross sectional study among children 0 - 15 years who attended the children out-patient HIV clinic of the department of Paedia- 
trics, University College Hospital (UCH) between January to March 2020. At each visit, the children are examined by a physician, undergo adherence and nutrition counselling and receive ARV refills. The children were recruited consecutively. Children $\mathrm{HIV}^{+}$(male and female) that were $(0$ - 15) years who attended anti retroviral clinic and who's parents volunteered to partake in the study were included. Lack of consent from the child's caregiver and children with any on-going febrile illness or history suggestive of other systemic disease such as hepatitis or tuberculosis was the exclusion criteria. Data on the socio demographic, immunologic, clinical, anthropometric status and ART regimen were collected.

\subsection{Anthropometric and Biochemical Measurements}

The height of children 0 - 23 months were measured using an infantometer scale (model: Seca417 mobile infantometer). Children 2 - 15 year's height and weight were measured using a combined anthropometric scale and stadiometer (model no: ZT-120). Weights and heights were taken to the nearest $0.1 \mathrm{~kg}$ and $0.1 \mathrm{~cm}$ respectively. A MUAC tape was wrapped around the arm at the midpoint mark to measure the mid upper arm circumference of children 0 - 5 years, measurements were taken to the nearest 0.1 centimetre. The Z-scores for weight, height and mid-upper arm circumference were computed based on the child's age and gender using the WHO Anthro and Anthro-plus software. HIV infection was diagnosed using HIV antibody assay by ELISA and western blot and for children under 18 months of age, HIV DNA detected by PCR. HIV viral load tests were done using COBAS $^{\circledR}$ AmpliPrep/COBAS $^{\circledR}$ TaqMan $^{\circledR}$ HIV-1 test, v2.0. Absolute CD4 count tests were done using the Sysmex Partec ${ }^{\circledR}$ Cyflow counter 11 flow cytometer and followed WHO laboratory guidelines for enumerating CD4 T-lymphocytes in the context of HIV.

\subsection{Definitions}

Stunting, wasting and underweight were defined as height-for-age z-score (HAZ), weight-for-height (WHZ) and weight-for-age z-score (WAZ) lower than-2 standard deviations (SD) respectively. Wasting was calculated using (WHZ) for children under five years of age, and body-mass-index-for-age z-score (BAZ) for children aged above five years. Immunodeficiency for age was defined following WHO immunological classification for children with established HIV infection where mild and insignificant immunodeficiency was $\% \mathrm{CD} 4^{+}>30$ among children younger than 12 months, $>25$ among children $12-35$ months or $>20$ in children over 36 months and CD4 count $>350$ per $\mathrm{mm}^{3}$ in older children.

\subsection{Statistics}

Frequencies and percentages were used to summarize the data. The weight-forheight, height-for-age, and weight-for-age z-scores were calculated using the WHO anthro for children under 5 years and anthro-plus software for children above 5 years. The Anthropometric status was categorized using the WHO (2006) 
reference standards. The prevalence of stunting, underweight, and wasting was calculated for the different age groups and genders, and the severity was classified based on z-scores. Differences in the proportions of wasting, stunting, and underweight between the boys and girls and at various ages were tested using the chi-square test. Pearson's correlation was used to test the association between nutritional status (HAZ) and other dependent variables. Other studies show that age, gender, stunting, viral load, CD4 count, and immunological classifications have been shown to confound stunting and so we adjusted for it. Regression analyses were done to determine the association between the independent variables and the confounding factors. Nutritional status (HAZ) among the children was studied using linear mixed models with an unstructured variance-covariance matrix. Associations between CD4 count, viral load, and HAZ were tested using regression models with age, gender, stunting, viral load, CD4 count, and immunological classifications considered as potential adjustment variables. All analyses were conducted using statistical package for social sciences (SPSS) version 22. A P value of $<0.05$ was considered statistically significant.

\subsection{Ethical Considerations}

Informed written consent was obtained from parents or guardians of all participant children. In addition, informed oral assent was obtained from children that were 7 years or older at the time of the study. The study was approved by the Institutional Review Board of the Joint University of Ibadan and University College Hospital, Ibadan with registration number UI/EC/19/0475.

\section{Results and Discussion}

\subsection{Description of the Sample}

In this survey $159 \mathrm{HIV}^{+}$children aged 0 - 15 years old were studied and were receiving ART. Descriptive characteristics of the sample are summarized in Table 1. The mean age at the survey was 10.5 (standard deviation 3.4 ), with $56.6 \%$ of the children above 10 years of age. Less than half $(42.1 \%)$ of the children were orphans out of which $21.4 \%$ were maternal orphans, $10.1 \%$ paternal and $10.7 \%$ were double orphans.

Majority (37.1\%) of the children had been receiving Antiretroviral Treatment for 5 - 9 years. Most (71.7\%) of the children were on first line while $28.3 \%$ were on the second line of ART. No significant difference was observed between the children's duration of ART and their gender $(\mathrm{P}>0.05)$. A few $(10.3 \%)$ of the children had immuno deficiency with $\mathrm{CD}^{+}$count (\%) less than $15 \%$, not many (19.9\%) had moderate immuno deficiency while $69.9 \%$ had no damage to their immune system. Also, there was no significant difference between gender and immuno deficiency among the children $(\mathrm{P}>0.05)$. More than two-third $(74.2 \%)$ of the children had achieved viral suppression while $25.8 \%$ had not yet achieved it. Sixty one percent of the children were on treatment for more than 5 years, and in $74.2 \%$ the viral load was undetectable (Table 2). 
Table 1. Demographic and clinical characteristics of the HIV-infected children attending UCH, Ibadan in $2020(\mathrm{~N}=159)$.

\begin{tabular}{cccc}
\hline Variables & Categories & $\mathrm{N}$ & $\%$ \\
\hline Total children & & 159 & 100.0 \\
\hline Sex & Male & 88 & 55.3 \\
& Female & 71 & 44.7 \\
\hline Age in months & 0 - 59 months & 15 & \\
& $60-119$ months & 54 & 34.0 \\
& $\geq 120$ months & 90 & 56.6 \\
\hline Orphan hood status & Maternal & 34 & 21.4 \\
& Paternal & 17 & 10.7 \\
& Double & 17 & 10.7 \\
& None & 91 & 57.2 \\
\hline Child's Primary caregiver & Parents & 119 & 74.8 \\
& Grandparents & 31 & 19.5 \\
& Other family parents & 9.7 \\
\hline
\end{tabular}

Table 2. Clinical characteristics of the HIV-infected children attending UCH, Ibadan in $2020(\mathrm{~N}=159)$.

\begin{tabular}{|c|c|c|c|}
\hline Variables & Categories & $\mathrm{N}$ & $\%$ \\
\hline \multicolumn{4}{|c|}{ Duration of ART } \\
\hline & $<1$ year & 10 & 6.3 \\
\hline & $1-4$ years & 52 & 32.7 \\
\hline & $5-9$ years & 59 & 37.1 \\
\hline & $\geq 10$ years & 38 & 23.9 \\
\hline \multicolumn{4}{|l|}{ Type of ART } \\
\hline & First line & 114 & 71.7 \\
\hline & Second line & 45 & 28.3 \\
\hline \multicolumn{4}{|l|}{ Viral load } \\
\hline & $<1000$ copies $/ \mathrm{ml}$ & 118 & 74.2 \\
\hline & $>1000$ copies $/ \mathrm{ml}$ & 41 & 25.8 \\
\hline \multicolumn{4}{|c|}{ Length of viral suppression } \\
\hline & $<1$ year & 14 & 11.8 \\
\hline & $1-4$ years & 59 & 50.0 \\
\hline & 5 - 9 years & 35 & 29.7 \\
\hline & $\geq 10$ years & 10 & 8.5 \\
\hline
\end{tabular}




\section{Continued}

Immunological stage

\begin{tabular}{|c|c|c|c|}
\hline & No immuno-deficiency & 129 & 81.1 \\
\hline & Mild immuno-deficiency & 12 & 7.5 \\
\hline & Advanced immuno-deficiency & 11 & 6.9 \\
\hline & Severe Immuno-deficiency & 7 & 4.4 \\
\hline \multicolumn{4}{|l|}{ Duration of ART } \\
\hline & $<5$ years & 62 & 39.0 \\
\hline & $>5$ years & 97 & 61.0 \\
\hline
\end{tabular}

\subsection{Nutritional Status}

Of the 159 children, $27.7 \%$ were stunted, $14.4 \%$ were wasted, and $13.6 \%$ were underweight (Table 3). Stunting was more prevalent in male (17.0\%) and in children 10 years and above (22\%). Wasting was higher in female children (8.1\%) and more in children 10 years and above. Underweight was more prevalent in children 5 - 9 years old. Children 120 - 180 months showed the highest incidence of stunting (22.0\%). A significant difference was observed between children's height for age and their age in months $(\mathrm{P}<0.05)$. However no significant difference was observed between weight for age, height for age and BMI for age of the children.

\subsection{Associations between Stunting, Viral Load and CD4+ Count}

Table 4 \& Table 5 showed the association between stunting, viral load and CD $4^{+}$ count using age and gender as covariates. There was a significant association ( $P$ $<0.05)$ between the viral load and the Height-for-age Z-scores of children studied. There was also a significant association $(\mathrm{P}<0.05)$ between the $\mathrm{CD} 4^{+}$ counts and age in months of the children.

\subsection{Discussion}

This study aimed to determine the relationship between the nutritional status and virological outcome of the children ( 0 - 15 years) attending the antiretroviral clinic at University College Hospital (UCH) Ibadan, Oyo State, Nigeria. Globally, it is estimated that $2.5 \%$ of all child deaths are associated with HIV infection and Africa remains the region most heavily affected, with $5 \%$ of all child deaths associated with HIV infection [11]. Nigeria accounted for 59\% of all new child HIV infections in the west and central Africa in 2016 [5]. Less than half (42.1\%) of the children were orphans out of which $21.4 \%$ were maternal orphans, $10.1 \%$ were paternal and $10.7 \%$ were double orphans. This is in agreement with a study by Oladokun et al. [12]. They attributed the increase to the fact that women are more likely than men to be infected by HIV and have a more progressive disease. The majority of Orphans in this study were still being cared for by members of their family, either by a living parent or grandparents. This was a similar trend 
Table 3. Prevalence of nutritional indicators by sex and age $(\mathrm{N}=159)$.

\begin{tabular}{cccc}
\hline & Stunted (\%) & Wasted (\%) & Underweight (\%) \\
\hline Sex & & & \\
Male & 17.0 & 6.3 & 6.1 \\
Female & 10.7 & 8.1 & 7.5 \\
p-value & 0.430 & 0.425 & 0.309 \\
\hline Age & & & \\
$0-59$ months & 1.9 & - & 3.0 \\
$60-119$ months & 3.7 & 3.1 & 10.6 \\
$\geq 120$ months & 22.0 & 11.3 & - \\
p-value & 0.003 & 0.169 & 0.696 \\
\hline
\end{tabular}

Table 4. Associations between stunting, viral load and $\mathrm{CD} 4^{+}$count.

\begin{tabular}{|c|c|c|c|c|c|c|c|c|c|c|}
\hline \multirow{2}{*}{ Regression model } & \multicolumn{3}{|c|}{$\begin{array}{l}\text { HAZ } \\
\mathrm{X}^{1}\end{array}$} & \multicolumn{3}{|c|}{$\begin{array}{c}\text { Gender } \\
\mathrm{X}^{2}\end{array}$} & \multicolumn{4}{|c|}{$\begin{array}{l}\text { Age in months } \\
\qquad \mathrm{X}^{3}\end{array}$} \\
\hline & $\beta$ & $\operatorname{SE}(\beta)$ & $\mathrm{P}$-value & $B$ & $\operatorname{SE}(\beta)$ & $\mathrm{P}$-value & $B$ & $\operatorname{SE}(\beta)$ & P-value & $\mathrm{R}^{2}$ (adjusted) \\
\hline Viral load & -0.196 & 0.090 & $0.022^{\mathrm{a}}$ & -0.125 & 0.003 & 0.136 & 0.109 & 0.260 & 0.175 & 0.025 \\
\hline $\mathrm{CD} 4^{+}$count & 0.149 & 0.017 & 0.074 & -0.004 & 0.050 & 0.960 & -0.178 & 0.001 & $0.031^{\mathrm{a}}$ & 0.054 \\
\hline
\end{tabular}

aThe mean $\mathrm{z}$-scores for different nutritional parameters were compared and the differences were found statistically insignificant $(\mathrm{P}>0.05)$.

Table 5. Mean differences between nutritional status and viral suppression among respondents.

\begin{tabular}{ccccc}
\hline Variable & Weight for Age & Height for Age & Weight for Height & BMI for Age \\
\hline & Mean (Z-scores) & Mean (Z-scores) & Mean (Z-scores) & Mean (Z-scores) \\
\hline Virally Suppressed & -0.47 & -1.18 & 0.57 & -0.48 \\
Not virally suppressed & -0.60 & -1.49 & 0.77 & -0.62 \\
p-value & 0.725 & 0.271 & 0.793 & 0.588 \\
\hline
\end{tabular}

in many African countries where children living with HIV largely depend on their family system [13]. The trend of these children being absorbed into their extended families was better suited for their emotional and perhaps nutritional wellbeing than institutional care. There is perhaps also the need to develop psycho social support programs for CLHIV in addition to strengthening family support.

Viral suppression was defined as any viral load greater than $1000 \mathrm{cp} / \mathrm{ml}$. This definition is in accordance with WHO recommendations in countries with limited resources [14]. This is similar to previous reports by Fokam et al., [15], these findings suggests that achieving the third pillar of the 90-90-90 is possible and could be reinforced with adequate nutrition in the frame of an effective ART [16]. 
Anthropometric measurement involves the measurement of body physical dimensions which are significant determinants of health and diseases. Good nutritional status is important for the optimal outcome of effective ART among children. Stunting prevalence in this study was $27.7 \%$ which is lower than the report of a similar study [17]. Being underweight is an indication of poor energy reserve and a predisposing factor for infection. Akorede and Abiola [18] concluded that since the nutritional status has a lot of effect on the future then adequate care should be given to the children at that tender age and the only way to achieve this, is more nutrition education for the mothers, most especially on the proper care of the children. The levels of stunting observed among the children (17.0\% males, 10.7\% females) agree with studies carried out by Fagbamigbe et al. [17] in which they reported that males had a higher preponderance to be stunted. Similar studies by [19] [20] show that boys were more stunted, wasted, and underweight in comparison with the girls. However, in [21] study on assessment of nutritional status and associated factors reported that there were no consistent differences between sexes regarding the occurrence of stunting but a higher prevalence of wasting and underweight was seen among the males.

It has been shown that deficiencies of nutrients may affect the immune function in ways that may influence viral expression and replication, which further affect the progression of HIV disease and mortality of the patient [22]. HIV gradually weakens a patient's immunity by attacking CD4 T-cells, resulting in the development of opportunistic infections [23]. Studies have confirmed that nutrient deficiencies are associated with immune dysfunction and accelerated progression to AIDS [24] [25]. Many factors, especially proper nutrition, can help decrease the severity of immunosuppression [26]. About $18.8 \%$ of the children had some form of immuno deficiency and this has been reported to be related to the late diagnosis of the HIV infection [27]. In this study, there were associations found between viral load and stunting and also between the age of the children and their $\mathrm{CD} 4^{+}$counts.

\section{Conclusion}

This study has shown that about three-quarters of the children had achieved viral suppression. The prevalence of stunting, wasting, and underweight among the children was $27.7 \%, 9.4 \%$, and $13.6 \%$ respectively. Stunting was observed among the children and was more prevalent among the males than females. A significant association was observed between the viral load and stunting and also between CD4 count and the age of the children $(\mathrm{P}<0.05)$. These indices reinforce the need for nutrition education and the provision of food supplements to improve the nutritional status of children infected with HIV.

\section{Conflicts of Interest}

The authors declare no conflicts of interest regarding the publication of this paper. 


\section{References}

[1] Global Nutrition Report (2017) Nourishing the Sustainable Development Goals. Development Initiatives, Bristol, 34.

[2] Lodha, R. and Kabra, S.K. (2015) Children, Health \& Nutritional Status of HIV Infected. Indian Journal of Medical Research, 141, 10-12.

https://doi.org/10.4103/0971-5916.154486

[3] Oniyangi, O., Awani, B. and Iregbu, K.C. (2006) The Pattern of Paediatric HIV/ AIDS as Seen at the National Hospital Abuja, Nigeria. Nigeria Journal of Clinical Practice, 9, 153-158.

[4] World Health Organization (WHO) (2008) The Global Burden of Disease: 2004 Update. Geneva, 16.

[5] United States Agency for International Development (UNAIDS) (2017) Ending AIDS: Progress towards the 90-90-90 Targets.

[6] United States Agency for International Development (UNAIDS) (2010) Report on the Global AIDS Epidemic. Joint United Nations Program on HIV/AIDS.

[7] Braitstein, P., Brinkhof, M., Dabis, F., et al. (2006) Mortality of HIV-1 Infected Patients in the First Year of Antiretroviral Therapy: Comparison between Low-Income and High-Income Countries. The Lancet, 367, 817-824. https://doi.org/10.1016/S0140-6736(06)68337-2

[8] Bolton-Moore, C., Mubiana-Mbewe, M., Cantrell, R.A., et al. (2007) Clinical Outcomes and CD4 Cell Response in Children Receiving Antiretroviral Therapy at Primary Healthcare Facilities in Zambia. JAMA, 298, 1888-1899.

https://doi.org/10.1001/jama.298.16.1888

[9] Amosu, A.M., Degun, A.M., Atulomah, N.O.S. and Olanrewju, M.F. (2011) A Study of the Nutritional Status of Under-5 Children of Low-Income Earners in a SouthWestern Nigerian Community. Current Research Journal of Biological Sciences, 3 , 578-585.

[10] World Health Organization (WHO) (2012) Global Monitoring Framework and Strategy for the Global Plan towards the Elimination of New HIV Infections among Children by 2015 and Keeping Their Mothers Alive (EMTCT).

[11] World Health Organization WHO (2009) Guidelines for an Integrated Approach to the Nutritional Care of HIV-Infected Children (6 Months-14 Years) Preliminary Version for Country Introduction. Geneva.

[12] Oladokun, R., Brown, B., Aiyetan, P., Ayodele, O. and Osinusi, K. (2009) Comparison of Socio-Demographic and Clinical Characteristics of Orphans and Non-Orphans among HIV-Positive Children in Ibadan, Nigeria. International Journal of Infectious Diseases, 13, 462-468. https://doi.org/10.1016/j.ijid.2008.08.017

[13] Naidoo, P., Donenberg, G., et al. (2014) Exploring Risk and Protective Mechanisms Associated with HIV Infection among Adolescents in South Africa. Journal of Psychology in Africa, 24, 232-240. https://doi.org/10.1080/14330237.2014.906080

[14] ANRS/CNS Groupe d'experts pour la prise en charge du VIH: Prise en charge des situations d'échec virologique 2017.

https://cns.sante.fr/wp-content/uploads/2017/01/experts-vih_echec.pdf

[15] Fokam, J., Billong, S.C., Jogue, F., Moyo Tetang Ndiang, S., Nga Motaze, A.C., Paul, K.N., et al. (2017) Immunovirological Response and Associated Factors amongst HIV-1 Vertically Infected Adolescents in Yaoundé 381 Cameroon. PLoS ONE, 12, e0187566. https://doi.org/10.1371/journal.pone.0187566

[16] Joint United Nations Programme on HIV/AIDS. Blood Safety and HIV: UNAIDS 
Technical Update 3971997.

[17] Fagbamigbe, A.F., Adebowale, A.S. and IkeOluwapo, A. (2019) An Assessment of the Nutritional Status of ART Receiving HIV-Orphaned and Vulnerable Children in South-West Nigeria. Heliyon, 5, e02925.

https://doi.org/10.1016/j.heliyon.2019.e02925

[18] Akorede, Q.J. and Abiola, O.M. (2013) Assessment of Nutritional Status of Under-Five Children in Akure South Local Government, Ondo State, Nigeria. IJRRAS, 14, 671-681. https://www.arpapress.com/Volumes/Vol14Issue3/IJRRAS 143 24.pdf

[19] Ohene, S.A., Addo, N.A., Zigah, F., Newman, M., Lartey, M., Romero, M.A., Ofori, S., Sheriff, T. and Ndanu, T. (2013) Evaluation of Antiretroviral Therapy (ART) Provision in an Early Cohort of Patients Initiating ART in Ghana. The Pan African Medical Journal, 16, 117. https://doi.org/10.11604/pamj.2013.16.117.3136

[20] Manyike, P., Chinawa, J., Ubesie, A., Obu, H., Odetunde, O. and Chinawa, A. (2014) Prevalence of Malnutrition among Pre-School Children in, South-East Nigeria. Italian Journal of Pediatrics, 40, 75. https://doi.org/10.1186/s13052-014-0075-5

[21] Jayatissa, R. (2012) Determinants of and Interventions for Malnutrition. The Ceylon Medical Journal, 57, 51-55. https://doi.org/10.4038/cmj.v57i1.4209

[22] Semba, R. and Tang, A. (1999) Micronutrients and the Pathogenesis of Human Immunodeficiency Virus Infection. British Journal of Nutrition, 81, 181-189. https://doi.org/10.1017/S0007114599000379

[23] Center for Disease Control (CDC) (2020) About HIV/AIDS. HIV Basics. HIV/AIDS. CDC. https://www.cdc.gov/hiv/basics/whatishiv.html

[24] Macallan, D. (1999) Wasting in HIV Infection and AIDS. Journal of Nutrition, 129, 238S-242S. https://doi.org/10.1093/jn/129.1.238S

[25] Fawzi, W. (2003) Micronutrients and HIV-1 Disease Progression among Adults and Children. Clinical Infectious Diseases, 37, S112-S116. https://doi.org/10.1086/375882

[26] Thimmapuram, R., Lanka, S., Esswein, A. and Dall, L. (2019) Correlation of Nutrition with Immune Status in Human Immunodeficiency Virus Outpatients. Missouri Medicine, 116, 336-339.

[27] Ba, S., Ba, N., Sembene, L., Anne, T., Dia, H., Ndiaye, J., Badiane, N. and Ndour, C. (2020) Factors Associated with Adverse Therapeutic Outcomes in People Living with HIV (PLHIV) Monitored in Roi Baudouin Health Care Center, Dakar, Senegal. World Journal of AIDS, 10, 23-35. https://doi.org/10.4236/wja.2020.101003 